\section{Ensaio sobre o experimental no curta-metragem brasileiro contemporâneo}

\section{Essay on the experimental work in contemporary brazilian short-} films

\section{Isabella Stefanin}

Universidade Estadual de Campinas. Instituto de Artes.

\section{RESUMO}

Emprestando dos escritos e o estilo do Jairo Ferreira, o ensaio retoma o que já foi o exercício experimental no país e investiga o que o passado pode dizer sobre o que significa inovar no presente. O curta-metragem foi essencial para a iniciação no cinema dos grandes nomes do Cinema Novo: Cacá Diegues, Glauber Rocha, Rogério Sganzerla, Paulo César Saraceni - todos experimentaram no formato menor. Embora hoje seja ainda verdade que muitos dos novos cineastas começam fazendo carreira em festivais com filme curta, cineasta amador não é sinônimo de cineasta experimental. Os festivais de cinema synonym for experimental filmmaker. The country's film festivals have do país institucionalizaram o termo "experimental" como um dos possíveis gêneros de realização de um filme. Por meio da análise de três curtas-metragens nacionais realizados entre 2010 e 2017, o ensaio busca investigar oqueérealmente a atividade de cinema de invenção no Brasil hoje. São apresentadas, ainda, hipóteses sobre a intersecção das cenas de produção de filme curta e a de filme experimental como ambas práticas marginais ao grande público, que é majoritariamente alimentado pela lógica narrativo-industrial do cinema mainstream. Entre pensamentos da história das artes, a reprodutibilidade técnica e a emancipação do cinema, o ensaio traz também o debate de arte versus indústria, ou o trabalho de artistas e o de fazedores de filmes.

PALAVRAS-CHAVE: cinema brasileiro, curta-metragem, filme experimental, artes visuais, festival de cinema. institutionalized the term "experimental" as one of the possible genres for making a film. Through the analysis of three national short films made between 2010 and 2017, the essay seeks to investigate what really is the activity of "invention cinema" in Brazil today. Hypotheses about the intersection of short film and experimental film production scenes are presented as both marginal practices for the general public, which is mainly fed by the narrative-industrial logic of mainstream cinema. Among thoughts in the history of the arts, technical reproducibility and the emancipation of cinema, the essay also brings up the debate of art versus industry, or the work of artists and that of moviemakers.

KEYWORDS: Brazilian cinema, shortfilm, experimental film, visual arts, film festival. 
“Seo experimentalnocinemabrasileiro (ounão) foiuma questãofundamentalmente de estética e será basicamente uma questão de estética, então é uma questão essencialmente de estética.

A música da estética. A luz da música. A estética da luz.

Cinema de invenção. Cinema: cinema. Cinema-cinema.

A estética da música. A luz da estética. Cinema.

O experimental: cinema universal. À luz de sua estética. Uma estética silenciosa porque musical. Uma estética musical porque silenciosa. Principalmente quando falada do início ao fim.

Invenção de uma outra estética. Invenção da música de outra ordem.Cinematografia: invenção permanente.

O experimental em nosso cinema (ou não): a música da luz.

Janela da câmera: pauta do autor da composição iluminada. O autor da experimentação cinematográfica usa essa janela como pauta musical. Estética da luz: música do experimental. Supra-sumo do cinema de invenção.

Não há essa de que um filme do experimental em qualquer latitude e em qualquer cinematografia nunca foi nem será ouvido: ele é ouvido. Ouça com olhos livres.

Se a música da luz foi vista e será vista, então é vista. Veja com ouvidos livres.

O experimental em nosso cinema é a música da mente livre. A iluminação de um novo

continente. A música de um novo ser da experimental cinematografia terrestre ou não. Estética visionária.

Cinema: poema. Autor de cinema: poeta. Experimental: profeta.

Experimental: antena. Cinema: a estética da luz."

Jairo Ferreira
Existe uma distinção clássica entre as artes que se materializam no espaço, como a pintura e escultura, e as artes que se desdobram no tempo, como a música e o teatro. Durante séculos os artistas contribuíram fundamentalmente para os avanços técnicos dos meios artísticos e desenvolvimento de diferentes práticas nas artes. $\mathrm{Na}$ pintura, por exemplo, foram responsáveis pelos experimentos realizados com a tinta e a tela, pelo aperfeiçoamento dos materiais, a preparação dos pigmentos. Assim, o mérito do visual na imagem artesanal era inteiramente do artista. Com o advento da imagem técnica, essa lógica foi rompida.

Não cabe aqui entrar na história da imagem técnica, mas pode-se sintetizar que ela foi um resultado da troca entre diferentes pesquisadores ao redor do mundo e ao longo de décadas, com inúmeras invenções tecnológicas com aplicações em diversas áreas do conhecimento científico. Durante todo o século XIX foram experimentações em captação, impressão, movimento e exibição para chegar nas técnicas primordiais do cinema. Nesse processo, em contrapartida à produção artesanal, a competência da produção pertence aos pesquisadores-cientistas, não ao artista que fez uso de técnica alheia.

A tecnologia da imagem em movimento serviu para unir as artes do espaço e do tempo, o estático e o movimento, a imagem e a música. Imagem pela luz e o cinema como música da luz. Ela aproximou a representação ao mundo sensível, oferecendo ao espectador diferentes ângulos de visão e oferecendo o trabalho dos olhos no movimento da câmera. Com a proposta de aproximação, cresceu alinhada à realidade, sem inteiramente se liberar de situações narrativas ou noções temporais lineares nem desafiar esse trabalho visual da percepção humana. A produção clássica, dominante e hegemônica, enraizada enquanto história do cinema, é narrativa-representativaindustrial, e foi ela que consolidou a grande indústria do cinema.

Em todos os textos de Adorno, o cinema era citado somente para criticar a indústria 
cultural, como um produto central e mais significativo dessa indústria que manipula seus consumidores, tira-Ihes a consciência e a autonomia e faz deles seu objeto passivo, reforçando o conformismo e a aceitação do status quo. Para Adorno, o cinema deixou todo seu potencial artístico de lado ao fazer uso de técnicas de reprodução mecânica e de produção em massa, transferindo uma motivação de lucro que aboliu qualquer possível autonomia enquanto obra de arte. Diz ainda que a pretensão do cinema em ser arte é ilegítima porque, ao contrário da arte, na indústria cultural a técnica permanece extrínseca ao objeto.

Em “Notas sobre o filme” (1966), porém, Adorno finalmente reconhece uma alternativa do que seria o "cinema emancipado". Ele dificilmente vai ter o selo de qualidade técnica financiado pela grande indústria, mas pode sim ter validação enquanto arte. O problema de Adorno foi ter vivido na Califórnia. É claro que as asserções do filósofo eram coerentes para Hollywood, mas desconsidera todo um trabalho de vanguarda experimentado desde o próprio surgimento do cinema. De fato, a técnica permanece extrínseca ao objeto, creditada aos pesquisadores-cientistas, mas ao artista cabe a aptidão própria de uso da tecnologia, a sinfonia de cores, ritmos e formas, a inovação na manipulação do dispositivo.

Existe uma outra história do cinema, uma marginal, que escapa do público da mesma forma que escapou de Theodor Adorno. Cinema emancipado. Cinema independente. Cinema de vanguarda. Cinema de invenção. Cinema underground. Cinema queer. Cinema marginal. Cinema experimental. Cinema do dispositivo. Cinema de artista. Cinema de museu. Não objetivo traçar um panorama dessa outra história, mas usar seus teóricos para entender as especificidades desse cinema e então abordar o curtametragem brasileiro contemporâneo sob a ótica do experimental.

O casal estadunidense de estudiosos do cinema Wheeler Winston e Gwendolyn Audrey traz contribuições acerca da produção experimental nos Estados Unidos e o filme queer. Para observações da produção no Reino Unido e Europa e a economia do cinema independente, utilizo o artista David Curtis. Cinema de Invenção, quase uma literatura experimental, do cineasta paulistano Jairo Ferreira, insere as mais claras e ao mesmo tempo menos precisas concepções sobre a estética e exercício experimentais. Com o artista mineiro radicado carioca André Parente, consigo conceituar as aproximações entre a forma fílmica e a arte plástica. Por último, cito toda a bibliografia quanto ao vídeo com um pedido de desculpas, pois não mantenho a diferenciação entre filme e vídeo na discussão de produções realizadas depois de 2010 no formato digital.

Além do experimental, há uma outra forma de cinema que possui uma definição muito vaga, circulação reduzida e obstáculos de mercado: o curta-metragem. No I Congresso da Indústria Cinematográfica Brasileira (Rio de Janeiro, 1972), em sessão plenária dedicada aos realizadores de curta-metragem, o produtor Luiz Fernando Graça Mello levantou a seguinte questão:

A definição do que é curta-metragem é bastante vaga, apesar de ter sido dada ao INC a incumbência de determiná-la. [...] De acordo com a legislação vigente, longas-metragens são filmes que têm duração superior a sessenta minutos, e curtas-metragens são aqueles que têm duração inferior a vinte minutos. Temos aqui um negócio engraçado: os filmes de vinte a sessenta minutos não existem. No entanto eles são produzidos.

O Instituto Nacional de Cinema (INC, 1966 - 1975) tomou, então, medidas que incentivariam a produção e circulação de curtas no país. A exibição seria compulsória, mas submetendo o produtor independente - a maioria gritante no caso do cinema de curta-metragem, que investia em seus próprios filmes e se encontraria posteriormente com grandes dívidas, estando sujeito às regras do mercado - às burocracias de seleção temática e tempo máximo estipulado em 10 minutos. De 
acordo com o livro "O filme curto" (SOUZA, 1980), a burocracia privava o curta de suas funções básicas, "a pesquisa, a experiência temática e de linguagem, bem como a introdução de novos cineastas". Para Jean-Claude Bernardet, o curta-metragem teve importância decisiva para a história do cinema brasileiro, a considerar que o Cinema Novo se iniciou na forma curta. É mais fácil, barato e acessível experimentar, inovar e pesquisar no formato menor.

Atualmente, passados os aborrecimentos do órgão de cinema associado à ditadura, conquistadas políticas públicas de incentivo e fomento ao audiovisual e filme de curtametragem, criados inúmeros festivais por todo o país que contemplem e prestigiem a forma curta e com mais escolas do ensino superior e técnico em audiovisual, muitos realizadores contemporâneos parecem levar a convicção de Bernadet de modo excessivamente literal. O curta-metragem não é só um longa enxugado, de fato possuindo estruturas e linguagens próprias, mas com as quais é inteiramente possível obedecer ao modelo narrativo-representativo-industrial.

Muitos cineastas têm inscrito seus curtas em festivais sob o "gênero experimental", quando na verdade pode ser apenas um cinema amador (ao invés de inovador) ou um cinema de ficção com temática de vanguarda (ao invés de cinema de vanguarda), por exemplo. O I Festival do Filme Brasileiro de Curta Metragem, realizado em 1965, em Salvador, instituía em seu regulamento três categorias de filmes de curta metragem, de duração máxima de trinta minutos, em 16 ou 35mm: Documentário, Experimental e Ficção. Essa categorização é mantida até hoje em editais e inscrições de festivais, ocasionalmente com o acréscimo da categoria Animação.

Se para Jairo Ferreira seus contemporâneos eram ainda a retaguarda da vanguarda, ficaria insatisfeito ao saber que hoje a experimentação éainda considerada um gênero. Para ele, o pensar em ser experimental não necessariamente seria estar experimental e o significante tem muito mais importância que o significado. Assim, o experimental 42 não pode ser um gênero, como se detentor de estilo e técnica próprios, quando é a ausência de propriedade que começa a fazer dele experimental. Seria a ausência de características comuns que reuniria uma coletânea de filmes experimentais. E se a ausência do comum vira um fator comum, então todo filme tem um pouco de experimental no seu significante, validando também a extinção do método como gênero.

Selecionei três filmes nacionais de 2010 a 2016 para abordar dentro da perspectiva do experimental, segundo critérios desenvolvidos na apresentação de cada filme. A proposta é entender como a prática se insere na produção contemporânea e contemplar os limites entre as barreiras formais-narrativas dos gêneros. Os filmes são "Fantasmas"(André Novais, MG, 2010), "Sem Título \#1: Dance of Leitfossil"(Carlos Adriano, SP, 2014) e "Maldição Tropical" (Luisa Marques, RJ, 2016).

Enquanto os outros dois selecionados fazem parte de uma nova geração de cineastas da contemporaneidade, Carlos Adriano já fazia filmes três décadas antes. Foi aluno da ECA, cresceu com o cinema marginal, frequentou os mesmos espaços do boca de lixo e conviveu, teve como mestre e produziu com o artista, cinéfilo, produtor, programador e agitador cultural Bernardo Vorobow. O filme "Sem Título \#1: Dance of Leitfossil" presta homenagem ao Vorobow e à colaboração entre os dois. Teoricamente.

"Dance of Leitfossil" é um filme de found footage. A dinâmica desse recurso consiste em exclusão e inclusão de arquivos que, ao serem reapropriados para o filme, respondem a uma nova ordem de significado. Assim, não é exatamente "documento encontrado", é documento selecionado e ressignificado, monumentalizado dentro do filme. Em teoria, o "Dance" é composto por três arquivos visuais diferentes: uma fotografia de Vassourinha, o sambista paulistano, usada anteriormente no documentário "A Voz e o Vazio: A Vez de Vassourinha", realizado por Carlos Adriano 
e Bernardo Vorobow; trechos da dança de Fred Astaire e Ginger Rogers em "Ritmo Louco" (1936); uma filmagem antiga sorridente de Vorobow. Ou uma criança que faz "shh" com a mão, um casal que dança e um velho que ri. Tudo isso ao som de Desfado, da Ana Moura.

Na sua introdução ao cinema underground americano, Sheldon Renan fala, acerca do vídeo, que houve uma progressão rumo à complexidade e à simplificação, podendose despender mais e gastar menos para fazer um filme. "Atribui-se a Jean Cocteau a afirmação de que o filme não se tornará uma arte até que seus materiais sejam tão baratos como o lápis e o papel. Esse ponto está se aproximando incessantemente. À medida que ele se aproxima, a liberdade aumenta, e o filme de arte pessoal se torna mais vital" (1967). Dance faz parte da série Apontamentos Para uma AutoCineBiografia (em regresso) composta por três curtas digitais e emancipados.

Ao contrário de filmes comerciais, os filmes artísticos não precisam seguir uma lógica de mercado ou se submeter a escolhas de marketing. Eles operam fora desse sistema, livres e autônomos da audiência de massa. Por outro lado, têm dificuldade em encontrar seu público, seja pelos altos custos de distribuição, seja pela característica de um cinema profundamente pessoal, que por ora não se entrega mastigado ao espectador. "Sem Título \#1: Dance of Leitfossil", o primeiro da autocinebiografia do Carlos Adriano, é um filme de luto que dificilmente conversaria com uma audiência que não fosse familiarizada com o cineasta, seu trabalho e sua proposta, ou ao menos com um corpus experimental de cinema; ainda assim, o contexto de cada imagem é subvertido na apreciação do filme e o sentido é dado pela montagem, possibilitando pelo espectador uma fruição (ainda que interrompida pelas telas pretas) que independe de suas origens.

Além do experimental, sugiro, segundo a conceituação do documentário de Fernão Ramos (2008), que o caráter biográfico do filme flerta com o domínio documental, como um documentário pós-moderno de arquivo e sem qualquer aproximação científica da objetividade ou razão, mas sim expressivo e sensorial.

O filme "Maldição Tropical" de Luisa Marques, se insere também entre os domínios do experimental e o documentário, além da ficção. O primeiro pela demonstração plástica da edição em uma sinfonia de cores, ritmos e formas sugestivas de abstração da matéria-movimento e a presença de imagens flutuantes que não são atribuídas a um personagem (suas ações ou sua psicologia), se liberando de uma situação narrativa; o segundo, nas asserções acerca do Brasil dos anos 50-60 cruzando a persona tropical Carmem Miranda com o Aterro do Flamengo, moderno complexo de lazer onde está localizado o Museu Carmem M; o terceiro, na narrativa de ficção científica desenvolvida com a história e o fantasma do passado.

Mas tanto faz, porque ele é demasiadamente queer para ser situado além da sua marginalização enquanto gênero experimental e filme de artista. O queer é um cinema transgressor, o esquisito, que não só rompe com o modelo clássico, mas também subverte seus elementos por meio da apropriação destes, por vezes aliado à estética camp ridicularizando a forma dominante. Uma exemplificação do deboche em "Maldição Tropical" é a caracterização do fantasma com apenas um pano branco que grita simultaneamente baixo orçamento e escolha deliberada de design.

Fez parte do projeto Curta Mulheres, que contou com 52 filmes ao longo de 12 meses feitos por diretoras mulheres de diferentes partes do Brasil. Apesar de não ser um filme de museu, compôs no Tate Modern, em Londres, a programação da exibição "Tropicália and Beyond: dialogues in Brazilian film history" sobre o legado da Tropicália e seus efeitos sobre a produção filmográfica no Brasil. Em "A History of Artists' Film and Video in Britain", David Curtis critica a concepção museológica de que a validação de um filme enquanto arte está na realização planejada para o ambiente de arte, o museu. Seja o fazedor de filme um pragmático ou visionário, ele 
vai aceitar a necessidade de criar para quem quiser exibir; o cinema emancipado é também livre dos luxos.

Houve uma disseminação massiva de diferentes termos para definir aqueles que experimentavam com filmes. Alguns se desgastaram, perderam sentido ou foram utilizados indiscriminadamente. Cineasta experimental, fazedor de filme, artista, artista de cinema, videoartista, independente. As diferenciações poderiam partir da origem do autor, fosse no cinema ou nas artes plásticas, ou do local de exibição, como em salas de cinema, espaços domésticos, televisão ou museus. No seu "ABC da Literatura", Ezra Pound faz uma classificação de escritores, cuja categoria mais nobre é a dos "inventores". Estes são os autores que descobriram um processo. Em "Cinema de Invenção", Jairo coloca os cineastas que descobrem novos processos como inventores.

André Novais, diretor de "Fantasmas", é um inventor. O filme é uma ficção realista ao mesmo tempo que propositor de debates do experimental. Dois amigos conversam na laje de uma casa, personagens e narrativa desenvolvidos no diálogo entre eles, enquanto a imagem é fixa da vista da laje e a cidade acontece como opção única à vista do espectador, enquanto os personagens permanecem omitidos. Eventualmente, a presença do dispositivo na laje é revelada sem que a quarta parede seja necessariamente quebrada e a câmera continua fazendo parte da diegese. Essa metalinguagem instaura a imagem da câmera como objeto de contemplação do espectador ao mesmo tempo que é objeto dos personagens. Quando tarjas pretas são adicionadas na imagem, ela se desloca para objeto de manipulação do personagem. A narrativa é clara. O Gabriel sente falta da Camila e grava a rua esperando que ela apareça, enquanto o amigo Maurílio diz que é uma má ideia e pede para parar a gravação. A Camila aparece e o Gabriel promete que agora vai conseguir esquecer a ex-namorada, só queria ter certeza. Ele não consegue esquecer e usa a imagem gravada para poder observar a Camila repetidamente. Essa lógica só é possível pela composição da imagem e do diálogo, ao mesmo tempo que a imagem de um posto de gasolina não possui lógica sozinho e o diálogo banal parece insignificante. 0 sentido na narrativa é dado pelo que nem aparece no quadro.

A câmera ligada percebida e verbalizada é o que justifica também ao público o porquê de estarem olhando para um posto de gasolina. A verbalização da câmera em um primeiro momento e o surgimento de tarjas pretas ao redor do quadro no segundo momento são os recursos que dividem esse filme em três registros: o objetivo, de contemplação; o subjetivado, ao enunciar a câmera e participar do fluxo de captação da imagem; o de recepção, ao externar o fluxo de captação para manipulação da imagem. Esses três registros podem também, de certa forma, passar pelos diferentes domínios ou gêneros dos nossos festivais. O primeiro remete à forma clássica narrativa na ficção, o espectador observa a realidade representada. O segundo se assemelha ao recuo do cinema direto, levando o espectador a questionar se aquela narrativa é ficcional ou apenas documentada. No terceiro momento, a demonstração de manipular a materialidade da imagem que o espectador acabou de presenciar sendo gravada se aproxima do cinema disruptivo e inventivo, se apropriando das tecnologias em uma nova forma de contar história.

Não existem limites concretos entre os domínios do cinema. O curta-metragem é um formato mais propício para a experimentação e possui uma linguagem própria, mas isso não significa que todo curta será experimental. O cinema de ficção tende a obedecer a uma lógica narrativa-representativa-industrial, mas as narrativas ficcionais podem ser criadas de muitas formas e alguns recursos podem ser pioneiros ou emprestados de inventividade emancipada. $O$ documentário parece possuir uma proposta clara, mas sua execução vai perpassar a ciência, a arte e/ou o drama. É compreensível que festivais precisem de categorização para executar sua curadoria, 
programação e premiação, mas não se pode deixar de discutir a coadjuvação dos gêneros e, ainda, como a separação deles pode acabar por silenciar o que é realmente a atividade experimental no país.

\section{REFERÊNCIAS}

ADORNO, Theodor. Notas sobre o filme (1966). In: Cohn, Gabriel (org.). Theodor W. Adorno. São Paulo, Ática, 1986

COCCHIARALE, Fernando (curad.); PARENTE, André (text.). Filmes de artista: Brasil, 1965-80. Rio de Janeiro, RJ: Metropolis: Contra Capa, 2007

CURTIS, David. A history of artists' film and video in Britain. London: BFI, 2007

DIXON, Wheeler W.; FOSTER, Gwendolyn Audrey. Experimental cinema: the film reader. London: Routledge, 2002

RAMOS, Fernão Pessoa; MIRANDA, Luiz Felipe. Enciclopédia do cinema brasileiro. 2. Ed

FERREIRA, Jairo. Cinema de invenção. São Paulo, SP: M. Limonad: EMBRAFILME, 1986 HISTORIA do cinema mundial. Coautoria de Fernando Mascarello. 3. ed. Campinas, SP: Papirus, 2008

LE GRICE, Malcolm. Experimental cinema in the digital age. London: BFI, 2001 MACDONALD, Scott. Avant-garde film: motion studies. Cambridge [Inglaterra]; New York, NY: Cambridge University Press, 1993

NASSAR, Kety Fernandes (Coord.). Rumos cinema e vídeo: linguagem expandidas 2012-2014. Organização de Claudiney José Ferreira; Tradução de Carmen Caballa. 7. ed. São Paulo, SP: Itaú Cultural, 2014

Centro de Pesquisa de Arte Brasileira. O filme curto. São Paulo, SP, 1980 2v. POUND, Ezra. ABC da literatura. São Paulo: Cultrix, 2006

RAMOS, Fernão Pessoa. Mas afinal...o que é mesmo documentário?. São Paulo, SP: 48
SENAC São Paulo, 2008

REES, A. L. A history of experimental film and video: from the canonical avant-garde to contemporary British practice. London: BFI, 1999

SOUZA, Carlos. O Filme Curto. Editora PMSP, São Paulo, 1980

XAVIER, Ismail. 0 discurso cinematográfico : a opacidade e a transparência. Rio de Janeiro, RJ: Paz e Terra, 1977

\section{FILMES}

FANTASMAS. André Novais Oliveira. Filmes de Plástico. 2010, 11 minutos, digital LEITFOSS/L Sem Título \#1: Dance of. Carlos Adriano. 2014, 5 minutos, digital TROPICAL Maldição A. Luisa Marques. 2017, 14 minutos, son., color., 16 mm 